Article

\title{
Parametric Optimization of Local Resonant Sonic Crystals Window on Noise Attenuation by Using Taguchi Method and ANOVA Analysis
}

\author{
Hsiao Mun Lee ${ }^{1} \mathbb{D}$, Yuting Hua ${ }^{1}$, Jinlong $X^{1, *}$ and Heow Pueh Lee $^{2} \mathbb{D}$ \\ 1 School of Mechanical and Electrical Engineering, Guangzhou University, 230 Wai Huan Xi Road, \\ Guangzhou 510006, China; hmlee@gzhu.edu.cn (H.L.M.); 2111907034@e.gzhu.edu.cn (Y.H.) \\ 2 Department of Mechanical Engineering, National University of Singapore, 9 Engineering Drive 1, \\ Singapore 117575, Singapore; mpeleehp@nus.edu.sg \\ * Correspondence: jlxie@gzhu.edu.cn
}

check for updates

Citation: Lee, H.M.; Hua, Y.; Xie, J.; Lee, H.P. Parametric Optimization of Local Resonant Sonic Crystals Window on Noise Attenuation by Using Taguchi Method and ANOVA Analysis. Crystals 2022, 12, 160. https://doi.org/10.3390/ cryst12020160

Academic Editors:

Kuo-Chih Chuang, Yanfeng Wang and Yongquan Liu

Received: 29 December 2021

Accepted: 20 January 2022

Published: 23 January 2022

Publisher's Note: MDPI stays neutral with regard to jurisdictional claims in published maps and institutional affiliations.

Copyright: (c) 2022 by the authors. Licensee MDPI, Basel, Switzerland. This article is an open access article distributed under the terms and conditions of the Creative Commons Attribution (CC BY) license (https:/ / creativecommons.org/licenses/by/ $4.0 /)$.

\begin{abstract}
Local resonant sonic crystals (LRSCs) window as a novel design has recently been proposed to achieve a good balance between noise mitigation, natural ventilation and natural lighting. In an effort to explore the feasibilities of such designs in civil residential buildings, an optimization methodology was proposed to develop a more compact LRSCs window with high noise attenuation performance in the present study. Specifically, the Taguchi method was adopted for the design of experiments on the parameters of interest and their corresponding levels, and SN ratio analysis was then applied for the parametric evaluations on the noise attenuation on specified frequencies in traffic noise (concentrated sound energy frequency range: 630-1000 Hz). Three optimal sets of design parameters on the interested frequencies, namely, $630 \mathrm{~Hz}, 800 \mathrm{~Hz}$ and $1000 \mathrm{~Hz}$ were obtained. ANOVA analysis was conducted to quantificationally identify the design parameters with statistical significance and remarkable contribution to the desired performance. Results indicate that the slit size has the most significant influence on the overall noise attenuation performance, followed by cavity width. An optimal set of design parameters to achieve the overall best noise reduction performance in the frequency range of $630-1000 \mathrm{~Hz}$ was finally determined by combining the SN ratio and ANOVA analysis. A prototype of the final optimized LRSCs window was then fabricated and tested in a semianechoic chamber. Good agreement was found between the experiment and numerical simulation. In comparison to the benchmark case, the final optimized design can achieve a further noise reduction by $2.84 \mathrm{dBA}, 3.48 \mathrm{dBA}$ and $5.56 \mathrm{dBA}$ for the frequencies of $630 \mathrm{~Hz}, 800 \mathrm{~Hz}$ and $1000 \mathrm{~Hz}$, respectively. The overall noise reduction for the interested frequency range can be promoted by $3.28 \mathrm{dBA}$. The results indicate that the proposed optimization methodology is practical and efficient in designing a high-performance LRSCs window or improving similar applications.
\end{abstract}

Keywords: local resonant sonic crystals window; noise attenuation; structure optimization; Taguchi method

\section{Introduction}

With the acceleration of urbanization, noise pollution has become the main source of urban environmental pollution. Noise regarded as unpleasant sound harms the public physical and mental health, and hence it is particularly important to reduce noise pollution with active or passive methods in our modern society [1,2]. Sonic crystals (SCs) as a passive noise attenuation method has recently received great attention from the research committee.

The concept of using sonic crystals (SCs) to reduce noise was first appeared in the 1990s [3,4]. SCs are normally periodically distributed sound scatterers that are forms of square or triangular lattices composed of two or more solid media. SCs can produce destructive Bragg interference in a certain frequency range. As a result, a band gap can be created and the noise at the specific frequency range can be attenuated [5-7]. Up to now, SCs have been widely applied in the designs of noise barriers and green belts that can be used 
in railway, expressway and some other public areas with noise pollution concerns [8-12]. Lee et al. [13] presented a maze structure that would be regarded as an SC structure. They reported that the maze structure can attenuate $17.9 \mathrm{dBA}$ noise in the frequency range below $1000 \mathrm{~Hz}$ and broaden the frequency band. Such structure was proposed to be used in children's playgrounds or gardens to reduce noise while providing a green landscape at the same time. Huang et al. [14] investigated the band gap attenuation mechanism of the natural SC of trees distributed in the urban area through theoretical and experimental methods. They noticed that hard soils and larger tree height were beneficial to obtain a wider band gap. However, for SCs, the band gap only appears when the wavelength of the sound wave is equal to or less than the lattice constant of the SCs, hence normal SCs are not suitable for the reduction of low-frequency noise.

Recently, the concept of local resonant sonic crystals (LRSCs) which have resonance characteristics has been proposed to reduce the lower frequency noise and broaden the band gaps with smaller SCs structures. Liu et al. [15] reported a pioneer work regarding the concept of LRSCs. They noticed that SCs with small size structures were able to reduce the low-frequency noise more effectively. A $2 \mathrm{~cm}$ lattice structure was reported to generate a band gap at about $400 \mathrm{~Hz}$. Cui et al. [16] introduced an SC with resonator cavity and slit. They found that the resonant cavity plays an important role in the band gap to achieve a lowfrequency acoustic absorption. Lardeau et al. [17] conducted numerical and experimental studies to investigate the acoustic characteristics of a system applying square-rod rigid scatterers that are composed of quarter wavelength resonators. They found that such a system can easily activate the coupling effects between the resonators to obtain a broadband gap of 590 to $3220 \mathrm{~Hz}$. Chen et al. [18] studied the acoustic performance of doublelayer plates cavity. It was observed that within a certain limit a better noise attenuation performance can be attained when the volume of the cavity was increased. Mohapatra et al. [19] studied the insertion loss of four different scatterers that were comprised of two cylindrical shells (inner and outer) but different configurations of the opening slit. It was discovered that the function of the outer shell tended to shift the resonance frequency of the scatterer to the low-frequency side while the inner shell indicated the opposite effect. The scatterers that had the outer shell with slit while the inner shell without slit can obtain a plurality of resonant bands with significant band width.

The Helmholtz resonator as a typical compact LRSC shows some excellent noise reduction characteristics and hence gains significant attention from the applications of noise control. Wang et al. [20] theoretically studied the band structure of one-dimensional SCs that applied Helmholtz resonators without any geometrical size restrictions. The interface response theory was applied to study the geometric effects on the band structures, transmission spectra, and defect states. The results indicated that the presence of Helmholtz resonators was apt to generate a band gap at a low frequency. The integration of single or periodical Helmholtz resonators can be practically applied in designing any acoustic band gap materials. Wang et al. [21] through theoretical and experimental methods studied the band structure and acoustic localization capability of a two-dimensional phononic crystal resonator (PCR) with slit design. They found that the structure of the resonator had a strong acoustic localization capability, and the resonant frequency and acoustic pressure amplification amplitude by PCR can be adjusted by regulating the geometric parameters of the slotted tube. According to the concepts of slow sound and critical coupling, Jimenez et al. [22] introduced an acoustic metamaterial panel that was made of periodic Helmholtz resonators (HRs). It was indicated that such an acoustic panel can acquire a perfect absorption of sound by controlling the geometry of the slit and HRs. Gupta et al. [23] investigated a muffler that has different shapes of Helmholtz resonators at the inlet by numerical and experimental studies. They reported that the use of Helmholtz resonators in the muffler can produce a lower resonate frequency to attenuate the low-frequency noise, and the proposed Helmholtz resonator with cylindrical shape can reduce the transmission loss up to $4.47 \mathrm{~dB}$ at $340 \mathrm{~Hz}$. Due to its excellent noise attenuation performance, studies were also carried out to investigate the geometric effects of the Helmholtz resonator on noise 
reduction. Selamet et al. [24] characterized the influences of length, shape and perforation of extension neck of Helmholtz resonator on the resonant frequency and transmission loss. It was found that the increase of neck length tended to reduce the resonance frequency and attenuation band when the cavity volume was kept constant. Li et al. [25] investigated the effects of slit size and number of slit openings of phononic crystal with embedded Helmholtz resonators on the bandgap characteristics. It was found that reducing the slit size led to a lower position and narrower band gap, and the design with one opening demonstrated a wider bandgap in a lower position than that of the design with two openings. Yang et al. [26] explored the effects of the slit width of the inner resonator of the dual/multilayer Helmholtz resonator on the multi-resonance tunneling of acoustic waves. They noticed that increasing the slit of the inner resonator can make the tunneling peaks shift to the high frequency.

Following the principles of the Helmholtz resonator, a novel concept of SCs window was proposed and tested in our previous studies [27-29]. The effects of resonator shapes, configurations and number of columns on the ventilation and noise attenuation of the SCs window were investigated. Results showed that the SCs window with the rectangular Helmholtz resonators exhibited the best noise reduction performance. However, in order to achieve a significant noise attenuation performance, the proposed SCs window was designed with a configuration of four columns of Helmholtz resonators. As a result, the overall thickness of the SCs window was up to $281.3 \mathrm{~mm}$ which exceeded the thickness of a normal outer wall (i.e., $220 \mathrm{~mm}$ ) of civil residential buildings in China. This restricts the potential application of such windows since some safety hazards such as protrusion from the walls, as well as the unpleasant facade of buildings, could be caused by installing such windows. Therefore, in order to reduce the overall thickness of the SCs window while maintaining or even enhancing the noise attenuation performance, the present study aims to propose an optimization methodology for the parametric designs of high-performance LRSCs window with less column of Helmholtz resonators and hence thinner window thickness. On the basis of the concept of our previous studies [27-29], the specific goal is to develop a high-performance LRSCs window with only three columns of Helmholtz resonators installed within a limited window thickness of $220 \mathrm{~mm}$.

\section{Methodologies}

According to our previous study [27-29], the configurations of the resonators in the SCs window including the geometries, arrays and relative positions were found to have a significant influence on the acoustic performance. However, the effort on a systematic optimization of these configuration parameters is still lacking. As shown in Figure 1, a prototype of the LRSCs window with the rectangular Helmholtz resonators in our previous study is demonstrated. The hollow rectangular aluminum tubes with an opening slit are arranged with 4 columns in the window to reduce noises while maintaining good performance in ventilation and natural lighting. The hollow rectangular aluminum tube is performed as a Helmholtz resonator, and the geometry of the hollow tube is sketched in Figure 1c. In literature, it is well known that the geometry of the resonator determines the resonance frequency of a Helmholtz resonator. Hence, the geometric parameters of the resonator such as the slit size $(a)$, length of the neck $(l)$, internal width $(b)$ and height $(c)$ are suggested to have a considerable impact on the noise attenuation performance of an LRSCs window. In the present study, numerical experiments combined with the optimization methods-the Taguchi method and analysis of variance method (ANOVA) to investigate the respective and comprehensive influences of these geometric parameters on the acoustic performance. Finally, an optimal set of parameters will be proposed and applied for the fabrication of an LRSCs window prototype with only three columns of resonators within an overall window thickness of $220 \mathrm{~mm}$. Experiments will be then conducted to investigate the noise attenuation performance of the prototype and verify the proposed design methodology. In the following sub-sections, details regarding the 
optimization method, procedures, numerical and experimental methods will be introduced and discussed.

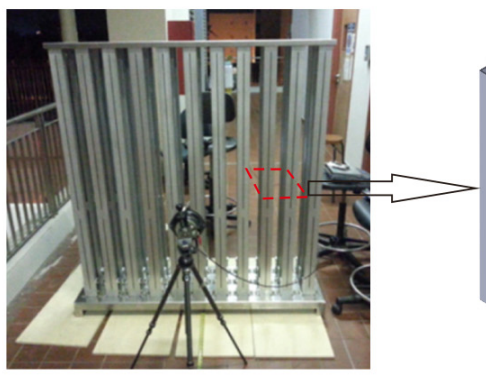

(a)

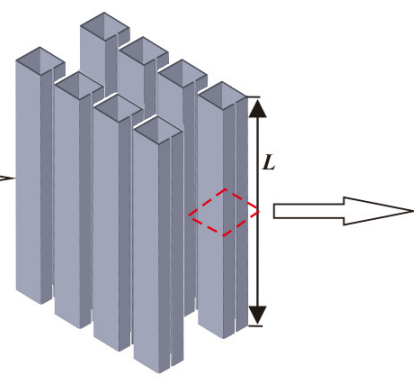

(b)

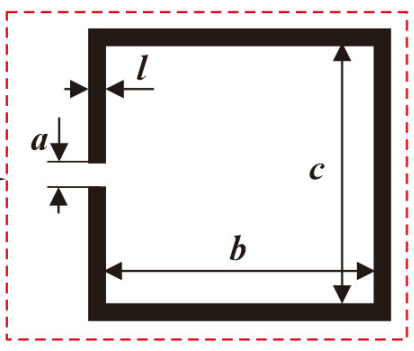

(c)

Figure 1. Illustrations of (a) a prototype of LRSCs window; (b) array of Helmholtz resonators (4 columns); (c) geometries of a rectangular Helmholtz resonator.

\subsection{Taguchi Method and The Design of Experiments}

The Taguchi method firstly introduced by Dr. Genichi Taguchi, is a widely used scientific method for the optimization of products or systems with multiple designs or operating variables. By a special design of orthogonal arrays with fewer experimental tests, it can obtain the same results as a full-factorial test after a systematic analysis of the results, and hence make the optimization process much more efficient. In practice, it is usually implemented together with the ANOVA method to explore the optimal operating (design) parameters of a system (product) to obtain the best performance (quality). Therefore, in order to design an LRSCs window with high noise attenuation performance, the Taguchi and ANOVA methods are applied to figure out the best geometric parameters of an LRSCs window with the rectangular hollow tubes according to our previous work [27-29]. In particular, the sensitivities of the geometric parameters such as $a, b, c$, and $l$ of the rectangular $\mathrm{SC}$ tubes on the noise reduction performance will be characterized as shown in Figure 1c.

In the Taguchi method, a signal-to-noise (SN) ratio is used to measure the quality characteristics deviating from the desired values. The desired objective, on the other hand, is determined by the related parameters to be assessed. For the SN ratio, the terms "signal" and "noise" stand for the desired and undesired effects for the output quality characteristics, respectively. In analysis, the quality characteristic can be generally divided into three categories: the-nominal-the-better, the-smaller-the-better and the-largerthe-better. In the present study, the quality characteristic obtained from the numerical experiments is the equivalent sound pressure level. Thus, in terms of the design objective, the smaller-the-better category is applied, and the SN ratio can be defined as:

$$
\mathrm{SN}=-10 \log \left[\frac{1}{N} \sum_{i=1}^{N} y_{i}^{2}\right]
$$

where $y_{i}$ is the result of the test, and $N$ is the number of repeated tests. Since numerical experiments are applied in the present study, the results of tests are assumed to be obtained under ideal conditions and therefore the impacts of the environment on the numerical results are ignored ( $N$ is set as 1$)$. The specific steps of the Taguchi method are applied as follows:

i. Identify the desired objective. The aims of the present study are to figure out the optimal geometric parameters of an LRSCs window in order to achieve the best noise reduction performance.

ii. Selection of quality characteristics and target values. As abovementioned, the quality characteristic is the equivalent sound pressure level, and the target value is set to be as small as possible. 
iii. Determine the critical control factors and corresponding levels. The proposed LRSCs window is used to attenuate noise by generating resonant frequencies through Helmholtz resonators, and the calculation of resonance frequency $\left(f_{c}\right)$ can be given by [30]:

$$
f_{c}=\frac{v}{2 \pi} \sqrt{\frac{S}{V(l+0.9 a)}}
$$

where $v$ is the speed of sound in air, $S$ is the cross-sectional area of the resonator opening, $V$ is the volume of resonator cavity, $l$ is the length of neck and $a$ is the slit size, as shown in Figure 1. According to Equation (2), related geometric parameters that determine the resonance frequency of a Helmholtz resonator are the slit size $(a)$, length of the neck $(l)$, internal width $(b)$ and height $(c)$ of the resonator. Hence, for brevity, Equation (2) can be further simplified as

$$
f_{c}=\frac{v}{2 \pi} \sqrt{\frac{a}{b c(l+0.9 a)}}
$$

The proposed configuration of resonators in the new LRSCs window is presented in Figure 2. In this study, the noise of interest to be attenuated by the LRSCs window is the traffic noise which has the concentrated sound energy in the frequencies from $630 \mathrm{~Hz}$ to $1000 \mathrm{~Hz}$. As aforementioned, the width of the LRSCs window is fixed at $220 \mathrm{~mm}$. The internal height $(c)$ of the resonator is also fixed at $57.5 \mathrm{~mm}$ which is selected according to the size of the LRSCs window. This is because the main influences of " $b$ " and " $c$ " are both to affect the volume of cavity volume of the resonator so that varying only the parameter " $b$ " is suggested to be good enough for the optimization analysis. Hence, the studied control factors to affect the equivalent sound pressure level include the slit size $\left(a_{1}, a_{2}\right.$ and $\left.a_{3}\right)$, the cavity width $\left(b_{1}, b_{2}\right.$ and $\left.b_{3}\right)$, and the neck length $l$ (maintained the same in the three columns). The values of the three levels of each control factor are summarized in Table 1. They are determined according to the fixed window thickness of $220 \mathrm{~mm}$ and the interested frequency band of noise. As shown in Figure 2, the first column of resonators is designed to attenuate the noise at the frequency of $630 \mathrm{~Hz}$, and therefore the levels of the control factors are calculated according to Equation (3) and the target frequency of $630 \mathrm{~Hz}$. The same principles are applied for the second and third column of the resonators which are designed to attenuate the noise at the frequencies of $800 \mathrm{~Hz}$ and $1000 \mathrm{~Hz}$, respectively. In this study, the influence of noise factor due to experiments is irrespective since the numerical experiments are conducted.

iv Orthogonal test table. In the Taguchi method, the size of the orthogonal test table is determined by the control factors and their relative levels. As discussed above, this orthogonal test considers seven control factors, and each control factor considers three levels. Therefore, the orthogonal test table of $\mathrm{L}_{18}\left(2^{1} \times 3^{7}\right)$ is applied as shown in Table 2. As can be seen, there are only 18 tests needed in comparison to a full-factorial test which requires $3^{7}=2187$ tests.

v Data analysis. After completing the 18 numerical tests in Table 2, the numerical results are then analyzed using the ANOVA method. The correction coefficient CF, the sum of squares for all tests $S_{T}$, the sum of squares for individual control factor $S_{Q}$, the variance of factor $V_{\text {factor }}$, the Fisher ratio $F$ and the contribution rate $\lambda$ of the individual control factor are calculated as follows: 


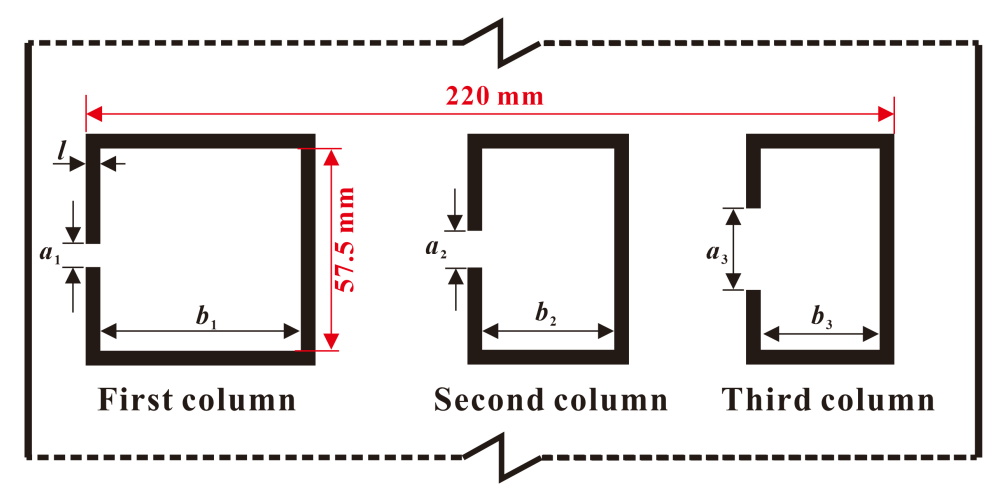

Figure 2. Control factors of the LRSCs structures in a single row of resonators.

Table 1. Summary of control factors and their relative levels.

\begin{tabular}{ccccc}
\hline & Control Factor & Level 1 & Level 2 & Level 3 \\
\hline$A$ & $a_{1}(\mathrm{~mm})$ & 4.3 & 6 & 8.8 \\
$B$ & $a_{2}(\mathrm{~mm})$ & 5.9 & 8 & 11.4 \\
$C$ & $a_{3}(\mathrm{~mm})$ & 12.6 & 20 & 42 \\
$D$ & $b_{1}(\mathrm{~mm})$ & 53.1 & 60 & 68.5 \\
$E$ & $b_{2}(\mathrm{~mm})$ & 34.2 & 37.5 & 41.4 \\
$F$ & $b_{3}(\mathrm{~mm})$ & 29.3 & 31.7 & 34.4 \\
$G$ & $l(\mathrm{~mm})$ & 2 & 3 & 4 \\
\hline
\end{tabular}

Table 2. $\mathrm{L}_{18}\left(2^{1} \times 3^{7}\right)$ orthogonal test table.

\begin{tabular}{|c|c|c|c|c|c|c|c|c|}
\hline Test Number & & $A$ & $B$ & $C$ & $D$ & $E$ & $F$ & $G$ \\
\hline 1 & 1 & 1 & 1 & 1 & 1 & 1 & 1 & 1 \\
\hline 2 & 1 & 1 & 2 & 2 & 2 & 2 & 2 & 2 \\
\hline 3 & 1 & 1 & 3 & 3 & 3 & 3 & 3 & 3 \\
\hline 4 & 1 & 2 & 1 & 1 & 2 & 2 & 3 & 3 \\
\hline 5 & 1 & 2 & 2 & 2 & 3 & 3 & 1 & 1 \\
\hline 6 & 1 & 2 & 3 & 3 & 1 & 1 & 2 & 2 \\
\hline 7 & 1 & 3 & 1 & 2 & 1 & 3 & 2 & 3 \\
\hline 8 & 1 & 3 & 2 & 3 & 2 & 1 & 3 & 1 \\
\hline 9 & 1 & 3 & 3 & 1 & 3 & 2 & 1 & 2 \\
\hline 10 & 2 & 1 & 1 & 3 & 3 & 2 & 2 & 1 \\
\hline 11 & 2 & 1 & 2 & 1 & 1 & 3 & 3 & 2 \\
\hline 12 & 2 & 1 & 3 & 2 & 2 & 1 & 1 & 3 \\
\hline 13 & 2 & 2 & 1 & 2 & 3 & 1 & 3 & 2 \\
\hline 14 & 2 & 2 & 2 & 3 & 1 & 2 & 1 & 3 \\
\hline 15 & 2 & 2 & 3 & 1 & 2 & 3 & 2 & 1 \\
\hline 16 & 2 & 3 & 1 & 3 & 2 & 3 & 1 & 2 \\
\hline 17 & 2 & 3 & 2 & 1 & 3 & 1 & 2 & 3 \\
\hline 18 & 2 & 3 & 3 & 2 & 1 & 2 & 3 & 1 \\
\hline
\end{tabular}

$$
\begin{gathered}
C F=\frac{\left(\sum_{j=1}^{n} \mathrm{SN}_{j}\right)^{2}}{n} \\
S_{T}=\sum_{j=1}^{n} \mathrm{SN}_{j}^{2}-C F \\
S_{Q}=\frac{\sum_{i=1}^{m} \mathrm{SN}_{i}^{2}}{n / m}-C F
\end{gathered}
$$




$$
\begin{gathered}
V_{\text {factor }}=\frac{S_{Q}}{D O F} \\
\lambda=\frac{S_{Q}-\left(V_{\text {error }} \times D O F\right)}{S_{T}} \\
F=\frac{V_{\text {factor }}}{V_{\text {error }}}
\end{gathered}
$$

where $n$ is the number of tests, $m$ is the number of levels for individual control factor; $\mathrm{SN}_{j}$ is the $\mathrm{SN}$ ratio of individual test, $\mathrm{SN}_{i}$ is the sum of $\mathrm{SN}$ ratios for a control factor at level $i\left(i=1,2\right.$ and 3); $D O F$ is the degree of freedom of a control factor, $V_{\text {error }}$ is the variance of error. The contribution rate $\lambda$ indicates the individual impact of individual control factor on the quality characteristic. The higher is the contribution rate, the more significant influence is the control factor.

\subsection{Numerical Methods}

Following the previous work [28], the "Pressure Acoustics, Frequency Domain" acoustic model in COMSOL software was employed for the two-dimensional (2D) acoustic simulations [31]. Rather than a full 3D simulation, the reasons for the selection of 2D simulations are the lower computation resource required and the capability that has been proved in similar problems [28,32,33]. As shown in Figure 3, the geometry of the 2D numerical model is corresponding to the experimental setup that is installed in a semi-anechoic chamber $(4.0 \mathrm{~m}(L) \times 3.6 \mathrm{~m}(W) \times 2.4 \mathrm{~m}(H))$. The radiation boundary condition which has been successfully employed by other researchers $[11,34,35]$ was applied for the boundaries of semi-anechoic chamber walls, indicating no reflection on these boundaries. For the rest of the walls, the sound hard boundary conditions were applied [11,34]. A monopole point source of $1 \mathrm{~Pa}$ was used to simulate the sound source, and a domain point probe was used as a virtual sensor to receive the sound signal. The material that fills up the fluid computation domain is air which has a density of $1.1839 \mathrm{~kg} / \mathrm{m}^{3}$ and sound speed of $343 \mathrm{~m} / \mathrm{s}$. Since the walls of the window structure are considered as sound hard boundaries, the material of the window is simply defined as aluminum which is the actual material of the fabricated SCs window in the experiments. In this numerical study, the calculated frequency range is from 100 to $5000 \mathrm{~Hz}$ which covers the main frequencies of traffic noise. In order to ensure the accuracies of simulation, a grid independent study was carried out and the final refined meshes with good quality were generated. Particularly, the maximum element size of the meshes was set to be less than one-sixth of the minimum wavelength, so that the effects of wavelength can be scrutinized. As shown in Table 3, the parameters in the setting of final grid systems are tabulated. For the 18 simulation cases listed in Table 2, the adopted grid systems consist of approximately 0.8 million elements with an average element quality higher than 0.95 . A typical mesh profile in the present study is illustrated in Figure 4.

Table 3. Parameters of the grid system in simulations.

\begin{tabular}{cc}
\hline Maximum element size $(\mathrm{m})$ & 0.00686 \\
\hline Minimum element size $(\mathrm{m})$ & 0.0001 \\
\hline Maximum element growth rate & 1.1 \\
\hline Curvature factor & 0.2 \\
\hline Resolution narrow regions & 1 \\
\hline
\end{tabular}




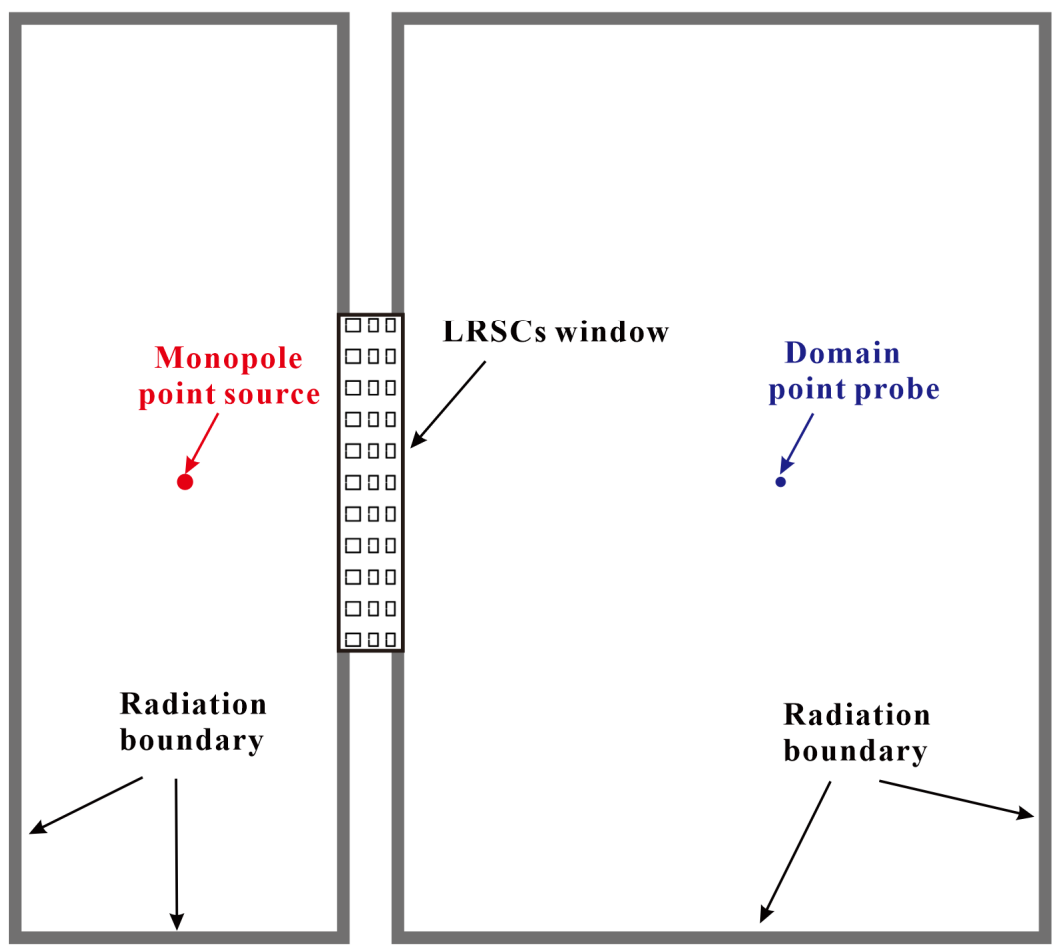

Figure 3. Boundary conditions applied in the 2D numerical model.

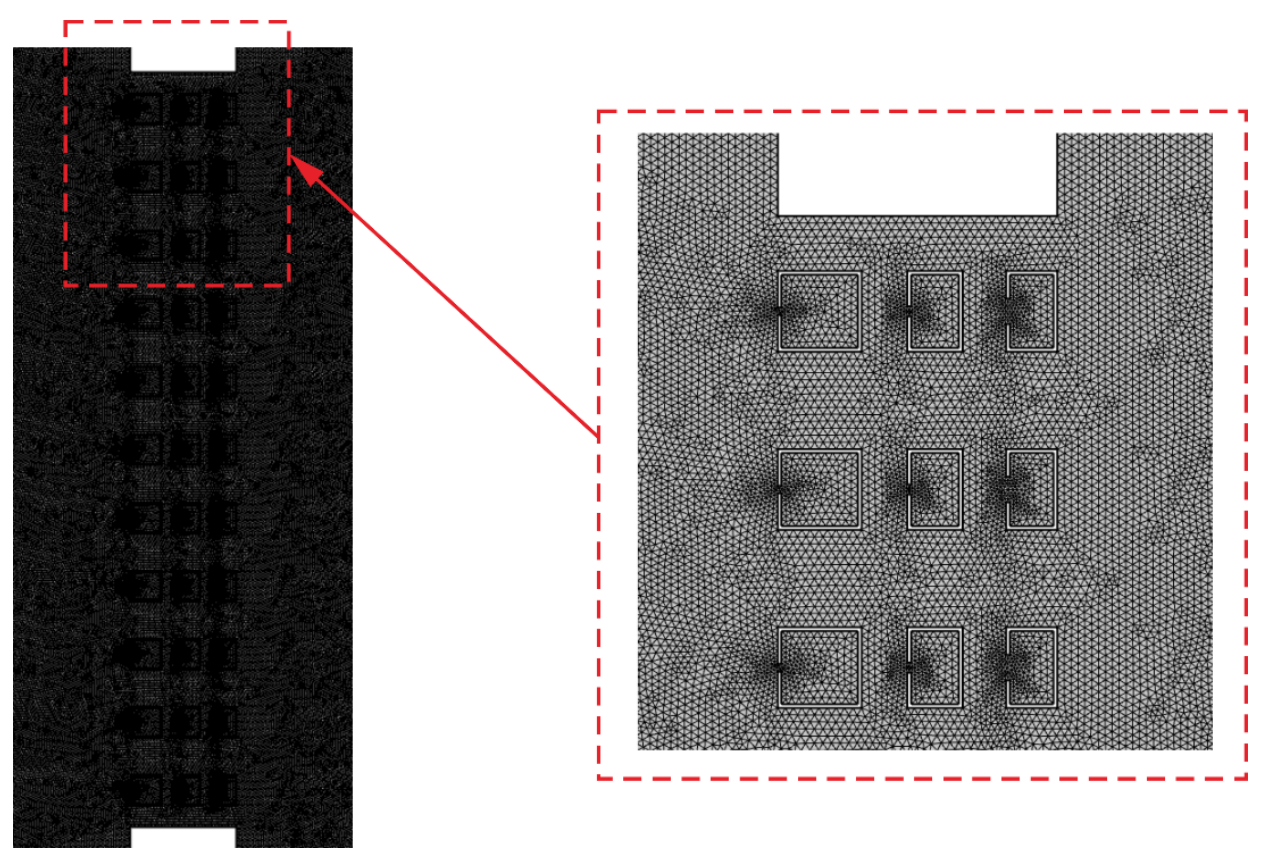

Figure 4. A typical mesh profile in the present study.

A detailed description of the proposed LRSCs window is illustrated in Figure 5a. It is comprised of 3 columns and 11 rows of rectangular hollow aluminum tubes. The thickness of the whole window is limited to $220 \mathrm{~mm}$, and the center distances between the first two columns and last two columns of resonators are fixed at $90.75 \mathrm{~mm}$ and $76.05 \mathrm{~mm}$, respectively. In order to have reasonable natural ventilation and lighting performance [29], the center distance between the two adjacent rows of resonators is fixed at $140 \mathrm{~mm}$, and the distance from the upper/bottom row of resonators to the window wall is fixed at $75 \mathrm{~mm}$. Under such configuration, the Bragg interference induced by the three columns of resonators will generate two band gaps which have the calculated center frequencies of 
$1890 \mathrm{~Hz}$ and $2255 \mathrm{~Hz}$, respectively. In comparison to the interested frequency range 630 to $1000 \mathrm{~Hz}$, the distances between the columns of resonators are supposed to have an insignificant influence on the targeted noise attenuation performance. Thus, the distances between the resonator columns are not considered in the optimization of geometric parameters. In this study, the benchmark window is a semi-push-open glass window that is widely used in civil residential buildings in China, as shown in Figure $5 b$.

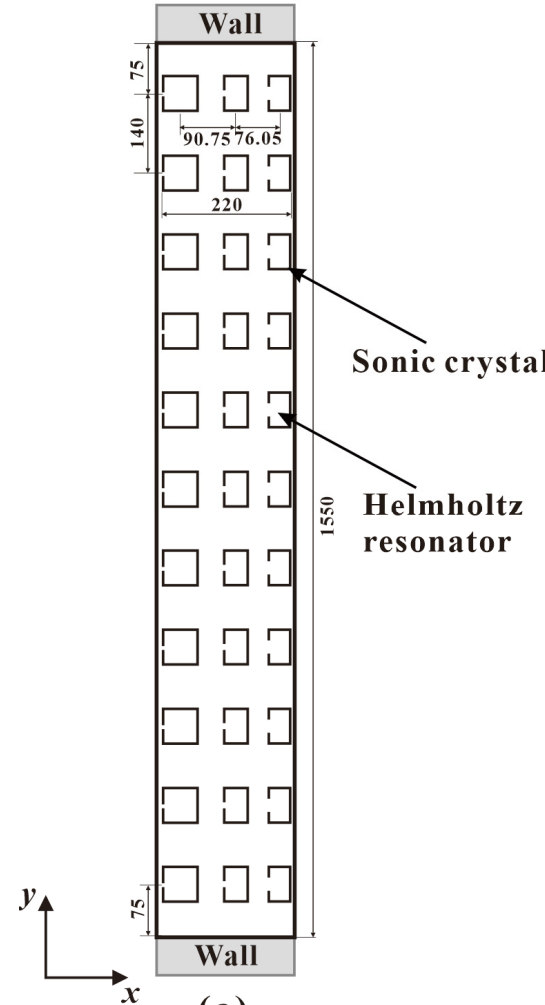

(a)

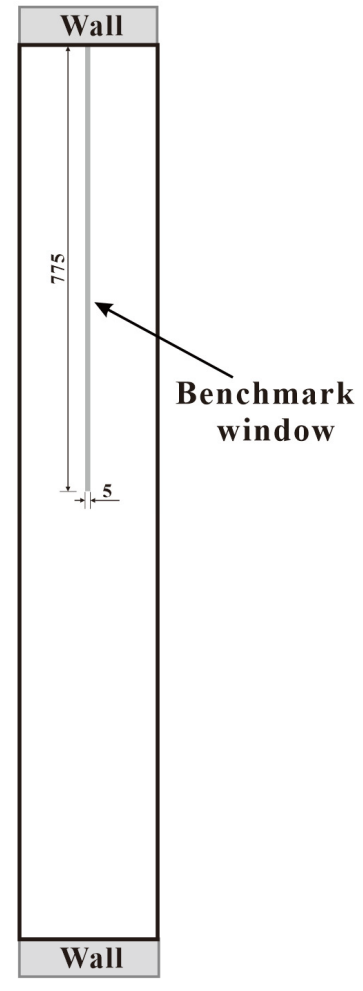

(b)

Figure 5. Schematic diagram of the tested windows: (a) LRSCs window, (b) Benchmark window (units: $\mathrm{mm}$ ).

\subsection{Experimental Methods}

A prototype of the LRSCs window with the final optimized geometric parameters from the Taguchi and ANOVA methods was fabricated, assembled and tested in a semianechoic chamber $(4.0 \mathrm{~m}(L) \times 3.6 \mathrm{~m}(W) \times 2.4 \mathrm{~m}(H))$, as shown in Figure 6 . The equipment employed in the experiments includes a YAMAHA power amplifier (model PX3), an SKC sound calibrator (model C224), three BSWA microphones (model MPA201), a BSWA dodecahedral non-directional sound source (model OS003A) and a BSWA data collector (model MC3642A). BSWA software (VA-Lab4) was installed in a computer for data collection and post-processing. In experiments, the white noise, pink noise and traffic noise were performed through the dodecahedral non-directional sound source. All sound pressure level data were collected by the microphones with the frequency range from $100 \mathrm{~Hz}$ to $5000 \mathrm{~Hz}$ and an interval of the center frequency of one-third octave band. The positions of the microphones (M1-M10) are indicated in Figure 6a. The sound pressure levels obtained in the same positions of simulations are therefore used for the comparison between the simulations and experiments. Detailed positions of the equipment and the LRSCs window can be found in Figure 6a,b. During the experiments, sound-absorbing panels were placed on the ground of the semi-anechoic chamber to prevent the reflection of sound waves from the ground as shown in Figure 6c. The simulated walls surrounding the LRSCs window were covered with soundproof material in order to reduce the sound wave diffraction around the window. 

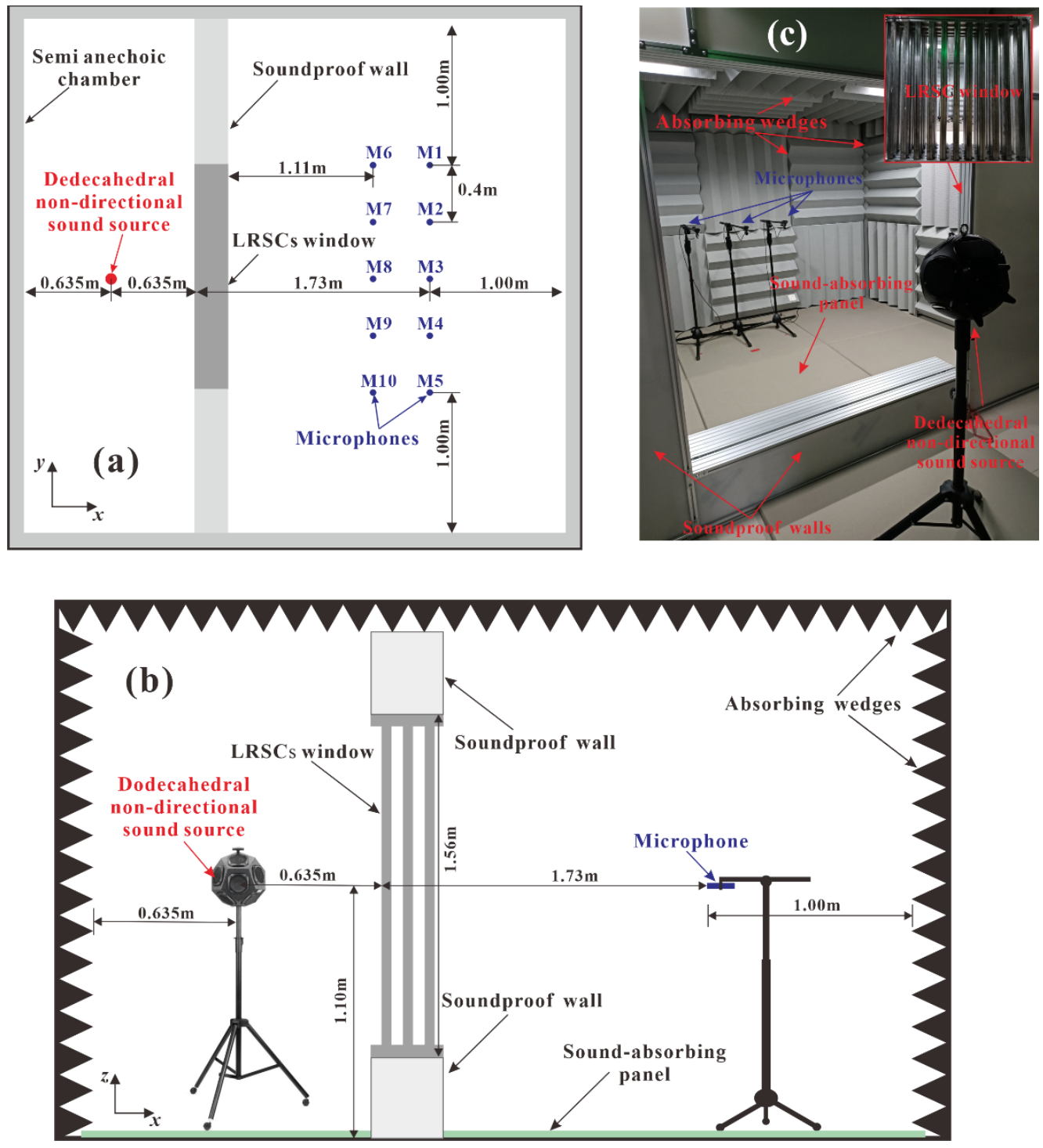

Figure 6. Experimental setup in the semi-anechoic chamber: (a) schematic of top view, (b) schematic of side view, (c) onsite experimental conditions.

\subsection{Evaluated Parameters}

For the results analysis, the equivalent sound pressure level $\left(L A_{e q}\right)$ of noise contribution at each frequency and the equivalent sound pressure level attenuation $\left(\Delta L A_{\text {eq }}\right)$ are defined as

$$
\begin{gathered}
L A_{e q}=10 \times \log \sum_{i=1}^{n} 10^{\frac{S P L_{i}}{10}} \\
\Delta L A_{e q}=L A_{e q b}-L A_{e q L R S C}
\end{gathered}
$$

where $S P L_{i}$ is the sound pressure level of each frequency, $L A_{\text {eqb }}$ and $L A_{\text {eqLRSC }}$ are the $L A_{\text {eq }}$ of the benchmark and LRSCs windows, respectively. For all experiments, the data obtained was the $L A_{e q}$ of one-third octave band. Hence, only the equivalent sound pressure level attenuation $\left(\triangle L A_{e q}\right)$ is calculated.

The attenuation performance of traffic noise by applying the LRSCs window is the focus of the present study. Hence, the frequency range of interest is from 630 to $1000 \mathrm{~Hz}$, which is the main frequency region of traffic noise with the concentrated sound energy. For this frequency range, three $1 / 3$ octave band center frequencies are included, namely, the $630 \mathrm{~Hz}, 800 \mathrm{~Hz}$ and $1000 \mathrm{~Hz}$, and their respective upper to lower frequencies are 
$562-708 \mathrm{~Hz}, 708-891 \mathrm{~Hz}$ and $891-1120 \mathrm{~Hz}$. The $1 / 3$ octave band is employed due to the fact that human hearing is more sensitive to the frequencies of this octave band. In the following sections, the $L A_{\text {eq }}-630 \mathrm{~Hz}, L A_{e q-}-800 \mathrm{~Hz}$ and $L A_{\text {eq }}-1000 \mathrm{~Hz}$ are the $L A_{\text {eq }}$ of the LRSCs window at $630 \mathrm{~Hz}, 800 \mathrm{~Hz}$ and $1000 \mathrm{~Hz}$, respectively.

\section{Results and Discussion}

\subsection{Optimizations Study}

In line with the orthogonal test table in Table 2, the equivalent sound pressure levels of the frequencies at $630 \mathrm{~Hz}, 800 \mathrm{~Hz}$ and $1000 \mathrm{~Hz}$ obtained from the 18 numerical tests are summarized in Table 4. The SN ratio for each frequency is calculated by Equation (1) and presented in Table 4 as well.

Table 4. Numerical results of the $L A_{e q}$ and the corresponding $\mathrm{SN}$ values.

\begin{tabular}{|c|c|c|c|c|c|c|}
\hline \multirow{2}{*}{ Test Number } & \multicolumn{2}{|c|}{$630 \mathrm{~Hz}$} & \multicolumn{2}{|c|}{$800 \mathrm{~Hz}$} & \multicolumn{2}{|c|}{$1000 \mathrm{~Hz}$} \\
\hline & $L A_{e q-630 \mathrm{~Hz}}(\mathrm{dBA})$ & $\mathrm{SN}_{630 \mathrm{~Hz}}(\mathrm{~dB})$ & $L A_{e q-800 \mathrm{~Hz}}(\mathrm{dBA})$ & $\mathrm{SN}_{800 \mathrm{~Hz}}(\mathrm{~dB})$ & $L A_{e q-800 \mathrm{~Hz}}(\mathrm{dBA})$ & $\mathrm{SN}_{1000 \mathrm{~Hz}}(\mathrm{~dB})$ \\
\hline 1 & 99.85 & -39.99 & 98.41 & -39.86 & 94.62 & -39.52 \\
\hline 2 & 101.99 & -40.17 & 97.06 & -39.74 & 93.82 & -39.45 \\
\hline 3 & 102.76 & -40.24 & 97.40 & -39.77 & 96.30 & -39.67 \\
\hline 4 & 97.40 & -39.77 & 93.21 & -39.39 & 100.30 & -40.03 \\
\hline 5 & 98.99 & -39.91 & 98.05 & -39.83 & 96.71 & -39.71 \\
\hline 6 & 100.54 & -40.05 & 102.59 & -40.22 & 94.71 & -39.53 \\
\hline 7 & 100.00 & -40.00 & 100.46 & -40.04 & 98.14 & -39.84 \\
\hline 8 & 100.95 & -40.08 & 98.52 & -39.87 & 96.84 & -39.72 \\
\hline 9 & 99.19 & -39.93 & 98.83 & -39.90 & 96.19 & -39.66 \\
\hline 10 & 101.47 & -40.13 & 99.78 & -39.98 & 100.51 & -40.04 \\
\hline 11 & 98.87 & -39.90 & 91.59 & -39.24 & 99.53 & -39.96 \\
\hline 12 & 103.61 & -40.31 & 102.80 & -40.24 & 89.84 & -39.07 \\
\hline 13 & 101.35 & -40.12 & 96.67 & -39.71 & 94.27 & -39.49 \\
\hline 14 & 98.90 & -39.90 & 97.82 & -39.81 & 101.02 & -40.09 \\
\hline 15 & 99.12 & -39.92 & 98.06 & -39.83 & 97.76 & -39.80 \\
\hline 16 & 98.25 & -39.85 & 102.06 & -40.18 & 102.72 & -40.23 \\
\hline 17 & 99.71 & -39.97 & 96.44 & -39.69 & 99.78 & -39.98 \\
\hline 18 & 103.86 & -40.33 & 97.17 & -39.75 & 90.78 & -39.16 \\
\hline
\end{tabular}

In the Taguchi method, the $\mathrm{SN}$ ratio analysis is applied to identify the optimal design parameters for the $L A_{e q}$ of the targeted frequencies at $630 \mathrm{~Hz}, 800 \mathrm{~Hz}$ and $1000 \mathrm{~Hz}$, respectively. The larger the value of the $\mathrm{SN}$ ratio, the better the quality characteristic. In order to achieve a comprehensive evaluation, the ANOVA analysis is conducted to determine the design parameters that are statistically significant and further quantify the contribution rate of each design parameter on the desired objective. With the assistance of these two methods, an optimal set of design parameters can be finally brought forward to develop an LRSCs window with high noise attenuation performance. In the following sub-sections, the results from the analysis of SN ratio and ANOVA are presented and discussed in detail.

\subsubsection{SN Ratio Analysis}

Based on the $\mathrm{SN}$ ratio obtained from the numerical tests, the averaged $\mathrm{SN}$ ratios for the three levels of each control factor are calculated and plotted in Figure 7. The mean SN ratio indicates the response or sensitivity of the control factor level on the quality characteristic. For a studied control factor, the level that achieves the highest mean SN ratio indicates the best for the desired performance. As shown in Figure 7, the optimal levels of the design parameters are highlighted in circles for the targeted frequencies. 

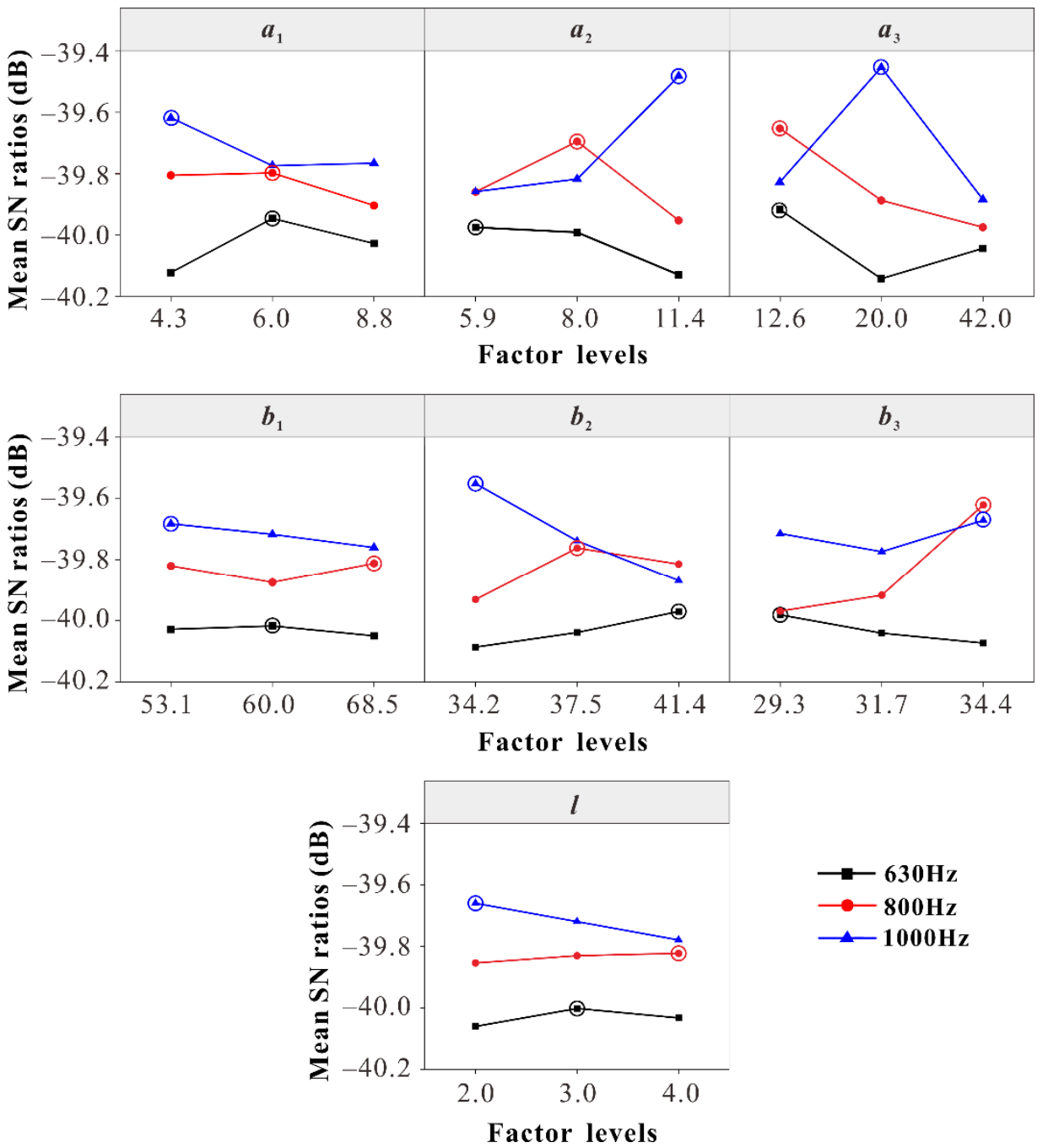

Figure 7. Response plots of the mean SN ratios for the frequencies of $630 \mathrm{~Hz}, 800 \mathrm{~Hz}$ and $1000 \mathrm{~Hz}$.

It is obvious that the optimal settings for the control factors on the performance of $630 \mathrm{~Hz}$ can be easily grouped as Set 1 , where $a_{1}=6.0 \mathrm{~mm}, a_{2}=5.9 \mathrm{~mm}, a_{3}=12.6 \mathrm{~mm}$, $b_{1}=60.0 \mathrm{~mm}, b_{2}=41.4 \mathrm{~mm}, b_{3}=29.3 \mathrm{~mm}$, and $l=3.0 \mathrm{~mm}$. Similarly, for the frequency of $800 \mathrm{~Hz}$, the optimal settings for the control factors can be grouped as Set 2, where $a_{1}=6.0 \mathrm{~mm}, a_{2}=8.0 \mathrm{~mm}, a_{3}=12.6 \mathrm{~mm}, b_{1}=68.5 \mathrm{~mm}, b_{2}=37.5 \mathrm{~mm}, b_{3}=34.4 \mathrm{~mm}$ and, $l=4.0 \mathrm{~mm}$. For the frequency of $1000 \mathrm{~Hz}$, the optimal settings for the control factors can be grouped as Set 3, where $a_{1}=4.3 \mathrm{~mm}, a_{2}=11.4 \mathrm{~mm}, a_{3}=20.0 \mathrm{~mm}, b_{1}=53.1 \mathrm{~mm}$, $b_{2}=34.2 \mathrm{~mm}, b_{3}=34.4 \mathrm{~mm}$ and $l=2.0 \mathrm{~mm}$ (Figure 7). To better understand the overall performance of these optimal sets, their equivalent sound pressure levels $L A_{e q}$ under different frequencies are tabulated in Table 5 . It is evident that the optimal set of parameters obtained under the specific frequency has indicated the best performance for that frequency among the three optimal sets. For instance, the optimal Set 1, Set 2 and Set 3 perform the best under the frequencies of $630 \mathrm{~Hz}, 800 \mathrm{~Hz}$ and $1000 \mathrm{~Hz}$, respectively. For the entire frequency range of $630-1000 \mathrm{~Hz}$, Set 1 achieves the best performance among the evaluated optimal sets, followed by Set 2 . From these results, it is expected that a truly comprehensive set of design parameters for the optimal performance of the entire frequency range $(630-1000 \mathrm{~Hz})$ should exist. However, the current simple application of SN ratio analysis is not able to deal with a comprehensive optimization problem. Hence, in order to convert the optimization problem from the multi-objectives (i.e., $630 \mathrm{~Hz}, 800 \mathrm{~Hz}$ and $1000 \mathrm{~Hz}$ ) to a single comprehensive objective $(630-1000 \mathrm{~Hz})$, the ANOVA analysis is then introduced. 
Table 5. The $L A_{e q}$ obtained by the numerical simulations of optimal sets of control factors (unit: $\mathrm{dBA}$ ).

\begin{tabular}{ccccc}
\hline Set & $\mathbf{6 3 0} \mathbf{H z}$ & $\mathbf{8 0 0} \mathbf{H z}$ & $\mathbf{1 0 0 0} \mathbf{H z}$ & $\mathbf{6 3 0 -} \mathbf{- 1 0 0 0} \mathbf{H z}$ \\
\hline $\mathbf{1}$ & 93.25 & 100.08 & 96.71 & 102.30 \\
$\mathbf{2}$ & 98.87 & 91.59 & 99.53 & 102.58 \\
$\mathbf{3}$ & 100.40 & 104.30 & 88.47 & 105.86 \\
\hline
\end{tabular}

\subsubsection{ANOVA Analysis}

As shown in Tables 6-8, the ANOVA analysis for the frequencies $630 \mathrm{~Hz}, 800 \mathrm{~Hz}$ and $1000 \mathrm{~Hz}$ are presented, respectively. These results are obtained with a level of confidence of $95 \%$ (the level of significance is 5\%). In the ANOVA analysis, a control factor with a $p$-value less than 0.05 means that this factor has a statistical significance on the output response. For a control factor that has a contribution rate larger than the contribution rate of error, it can be considered as a significant factor on the desired performance. Hence, by combining the contribution rate $(\lambda)$ and the mean SN ratio of the control factors, the overall significance of the control factors on the noise reduction performance can be characterized individually.

Table 6. ANOVA for $630 \mathrm{~Hz}$.

\begin{tabular}{ccccccc}
\hline Factor & $\begin{array}{c}\text { Degree of } \\
\text { Freedom }\end{array}$ & $\begin{array}{c}\text { Sum of Square } \\
\left(S_{Q}\right)\end{array}$ & $\begin{array}{c}\text { Variance } \\
\left(V_{\boldsymbol{e}}\right)\end{array}$ & $\boldsymbol{F}$-Ratio & $\boldsymbol{p}$-Value & $\begin{array}{c}\text { Contribution } \\
\text { Rate } \lambda(\mathbf{\%})\end{array}$ \\
\hline $\boldsymbol{a}_{\mathbf{1}}$ & $\mathbf{2}$ & $\mathbf{0 . 0 9 3}$ & $\mathbf{0 . 0 4 7}$ & $\mathbf{1 2 . 4 0}$ & $\mathbf{0 . 0 3 5}$ & $\mathbf{2 0 . 2 6}$ \\
$\boldsymbol{a}_{\mathbf{2}}$ & $\mathbf{2}$ & $\mathbf{0 . 0 8 6}$ & $\mathbf{0 . 0 4 3}$ & $\mathbf{1 1 . 4 5}$ & $\mathbf{0 . 0 3 9}$ & $\mathbf{1 8 . 5 7}$ \\
$\boldsymbol{a}_{\mathbf{3}}$ & $\mathbf{2}$ & $\mathbf{0 . 1 5 3}$ & $\mathbf{0 . 0 7 6}$ & $\mathbf{2 0 . 2 7}$ & $\mathbf{0 . 0 1 8}$ & $\mathbf{3 4 . 2 5}$ \\
$b_{1}$ & 2 & 0.003 & 0.002 & 0.43 & 0.686 & 0.00 \\
$b_{2}$ & 2 & 0.041 & 0.020 & 5.41 & 0.101 & 7.83 \\
$b_{3}$ & 2 & 0.026 & 0.013 & 3.46 & 0.166 & 4.37 \\
$l$ & 2 & 0.010 & 0.005 & 1.35 & 0.382 & 0.62 \\
Error & 3 & 0.011 & 0.004 & & & 14.09 \\
Total & 17 & 0.423 & & & & 100.00 \\
\hline
\end{tabular}

Table 7. ANOVA for $800 \mathrm{~Hz}$.

\begin{tabular}{ccccccc}
\hline Factor & $\begin{array}{c}\text { Degree of } \\
\text { Freedom }\end{array}$ & $\begin{array}{c}\text { Sum of Square } \\
\left(S_{Q}\right)\end{array}$ & $\begin{array}{c}\text { Variance } \\
\left(V_{\boldsymbol{e}}\right)\end{array}$ & $\boldsymbol{F}$-Ratio & $\boldsymbol{p}$-Value & $\begin{array}{c}\text { Contribution } \\
\text { Rate } \boldsymbol{\lambda} \mathbf{( \% )}\end{array}$ \\
\hline$a_{1}$ & 2 & 0.042 & 0.021 & 6.94 & 0.075 & 3.21 \\
$\boldsymbol{a}_{\mathbf{2}}$ & $\mathbf{2}$ & $\mathbf{0 . 2 0 3}$ & $\mathbf{0 . 1 0 1}$ & $\mathbf{3 3 . 5 6}$ & $\mathbf{0 . 0 0 9}$ & $\mathbf{1 7 . 6 1}$ \\
$\boldsymbol{a}_{\mathbf{3}}$ & $\mathbf{2}$ & $\mathbf{0 . 3 3 2}$ & $\mathbf{0 . 1 6 6}$ & $\mathbf{5 5 . 0 3}$ & $\mathbf{0 . 0 0 4}$ & $\mathbf{2 9 . 2 1}$ \\
$b_{1}$ & 2 & 0.014 & 0.007 & 2.33 & 0.245 & 0.72 \\
$b_{2}$ & 2 & 0.090 & 0.045 & 14.93 & 0.028 & 7.53 \\
$\boldsymbol{b}_{\mathbf{3}}$ & $\mathbf{2}$ & $\mathbf{0 . 4 2 3}$ & $\mathbf{0 . 2 1 2}$ & $\mathbf{7 0 . 1 1}$ & $\mathbf{0 . 0 0 3}$ & $\mathbf{3 7 . 3 7}$ \\
$l$ & 2 & 0.003 & 0.002 & 0.53 & 0.636 & 0.00 \\
Error & 3 & 0.009 & 0.003 & & & 4.34 \\
Total & 17 & 1.116 & & & & 100.00 \\
\hline
\end{tabular}

From Table 6 , the control factors with statistical significance $(p$-value $<0.05)$ for the frequency of $630 \mathrm{~Hz}$ are $a_{1}, a_{2}$ and $a_{3}$ which have contribution rates of $20.26 \%, 18.57 \%$ and $34.25 \%$ (the error contribution is $14.09 \%$ ), respectively. The results reveal that the slit size of the third column resonator $\left(a_{3}\right)$ imposes the most significant influence on the noise reduction at this frequency, followed by the slit size of the first column resonator $\left(a_{1}\right)$.

From Table 7, the ANOVA analysis for $800 \mathrm{~Hz}$ shows that the statistical significance ( $p$-value $<0.05)$ control factors are $a_{2}, a_{3}$ and $b_{3}$ which have contribution rates of $17.61 \%$, $29.21 \%$ and $37.37 \%$ (the error contribution is $4.34 \%$ ), respectively. The cavity width of the third column resonator $\left(b_{3}\right)$ shows a more significant impact on the noise reduction at this frequency, followed by the slit size of the third column resonator $\left(a_{3}\right)$. 
Table 8. ANOVA for $1000 \mathrm{~Hz}$.

\begin{tabular}{ccccccc}
\hline Factor & $\begin{array}{c}\text { Degree of } \\
\text { Freedom }\end{array}$ & $\begin{array}{c}\text { Sum of Square } \\
\left(S_{Q}\right)\end{array}$ & $\begin{array}{c}\text { Variance } \\
\left(V_{\boldsymbol{e}}\right)\end{array}$ & $\boldsymbol{F}$-Ratio & $\boldsymbol{p}$-Value & $\begin{array}{c}\text { Contribution } \\
\text { Rate } \boldsymbol{\lambda} \mathbf{( \% )}\end{array}$ \\
\hline$a_{1}$ & 2 & 0.092 & 0.046 & 3.65 & 0.157 & 3.93 \\
$\boldsymbol{a}_{\mathbf{2}}$ & $\mathbf{2}$ & $\mathbf{0 . 5 1 0}$ & $\mathbf{0 . 2 5 5}$ & $\mathbf{2 0 . 2 8}$ & $\mathbf{0 . 0 1 8}$ & $\mathbf{2 8 . 6 2}$ \\
$\boldsymbol{a}_{\mathbf{3}}$ & $\mathbf{2}$ & $\mathbf{0 . 6 5 5}$ & $\mathbf{0 . 3 2 7}$ & $\mathbf{2 6 . 0 4}$ & $\mathbf{0 . 0 1 3}$ & $\mathbf{3 7 . 1 8}$ \\
$b_{1}$ & 2 & 0.018 & 0.009 & 0.72 & 0.554 & 0.00 \\
$\boldsymbol{b}_{\mathbf{2}}$ & $\mathbf{2}$ & $\mathbf{0 . 3 0 7}$ & $\mathbf{0 . 1 5 3}$ & $\mathbf{1 2 . 2 0}$ & $\mathbf{0 . 0 3 6}$ & $\mathbf{1 6 . 6 2}$ \\
$b_{3}$ & 2 & 0.032 & 0.016 & 1.26 & 0.401 & 0.39 \\
$l$ & 2 & 0.043 & 0.021 & 1.70 & 0.320 & 1.05 \\
Error & 3 & 0.038 & 0.013 & & & 12.21 \\
Total & 17 & 1.693 & & & & 100.00 \\
\hline
\end{tabular}

As for the frequency of $1000 \mathrm{~Hz}$ in Table 8, the ANOVA results indicate that the slit size of the third column resonator $\left(a_{3}\right)$ is the most significant factor which has a percentage of contribution up to $37.18 \%$ and followed by the slit size of the second column resonator $\left(a_{2}\right)$, and then the cavity width of the second column resonator $\left(b_{2}\right)$.

In order to have a full-scale view of the ANOVA results, the contributions rates of the control factors and the associated errors are illustrated in Figure 8. Generally, it can be found that the slit size $(a)$ of the resonators has the most significant influence on the noise attenuation performance of the frequency range 630-1000 Hz and followed by the cavity width $(b)$. Whereas the neck length $(l)$ of the resonators indicates negligible effects on the final performance. This could be due to the fact that the slit size determines the speed of airflow in and out of the cavity of the resonator, which directly affects the resonant frequency and thereby the noise attenuation performance. The same explanation is also applied to the effects of the cavity width which solely determines the volume of the cavity of the resonator in the present study.
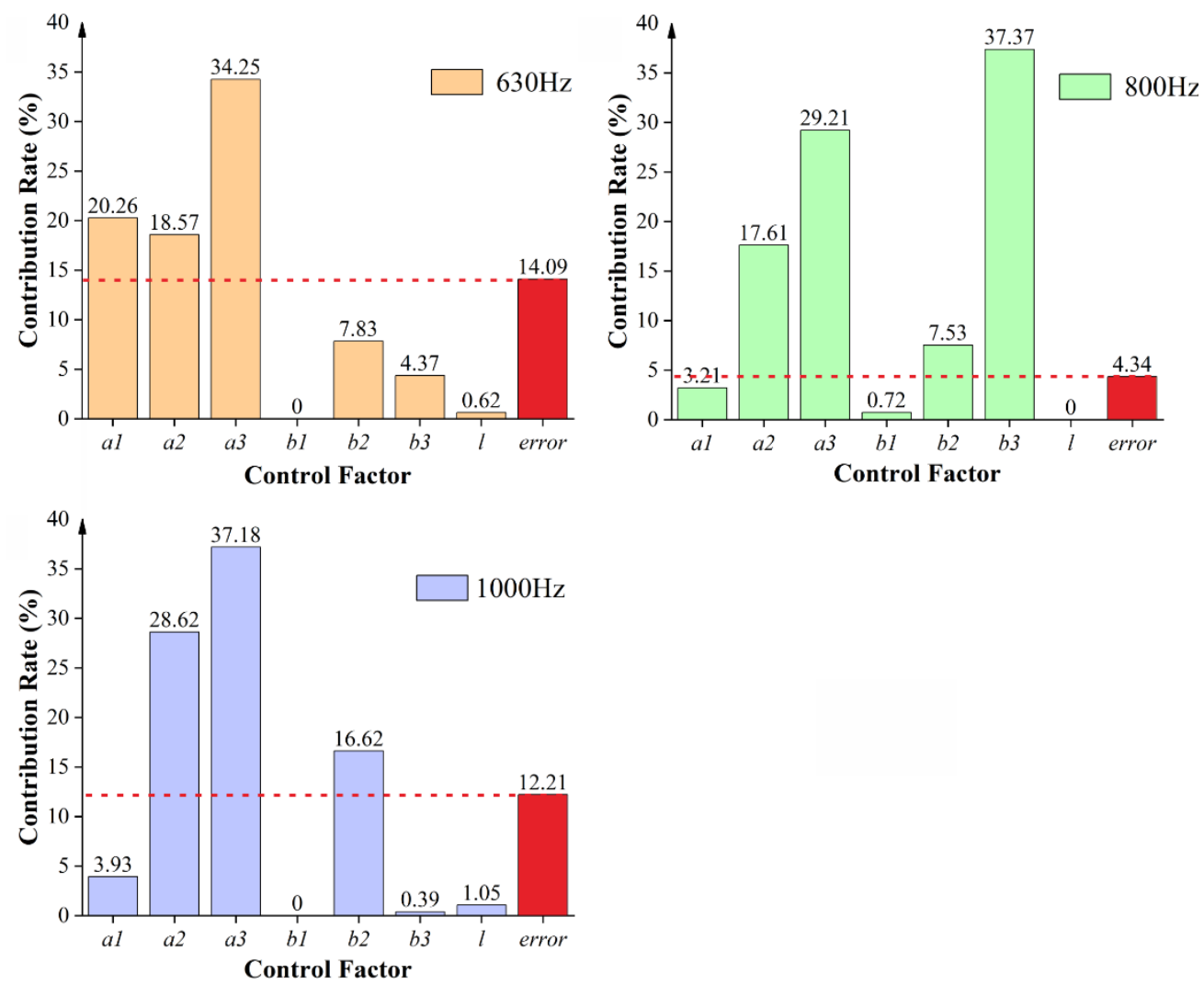

Figure 8. Contribution rates of control factors at different frequencies. 
Comprehensive optimization of the control factors on the noise attenuation performance of the frequency range $630-1000 \mathrm{~Hz}$ can be performed by combining the analysis in Figures 7 and 8. As aforementioned, the mean $\mathrm{SN}$ ratios of the design parameters (control factors) are as large as possible for the optimization by Taguchi analysis. From Figure 8, it can be seen that the control factor $a_{1}$ only has a remarkable effect on $630 \mathrm{~Hz}$. Therefore, the optimal value of $a_{1}$ can be simply selected as the one which has the maximum mean SN ratio at $630 \mathrm{~Hz}$ : $6 \mathrm{~mm}$. Similarly, the optimal value of the control factor $b_{3}$ is selected as $34.4 \mathrm{~mm}$ which has the maximum mean $\mathrm{SN}$ ratio at $800 \mathrm{~Hz}$ as shown in Figure 7. For the control factor $a_{2}$, significant impact is observed for all three frequencies. Since $a_{2}$ is originally used in Equation (3) for the design of the second column resonator for the noise attenuation at $800 \mathrm{~Hz}$, the optimal value of $a_{2}$ is selected at $8 \mathrm{~mm}$ which achieves the maximum mean SN ratio at $800 \mathrm{~Hz}$. Following the same principle, the optimal values of $a_{3}$ and $b_{2}$ are therefore selected at $20 \mathrm{~mm}$ and $37.5 \mathrm{~mm}$, respectively. For $b_{1}$, it is manifested as an insignificant factor in the ANOVA analysis. However, as it is originally designed to account for the noise attenuation at $630 \mathrm{~Hz}$, the optimal value of $b_{1}$ is selected at $60 \mathrm{~mm}$ which has the maximum mean SN ratio at $630 \mathrm{~Hz}$ from the Taguchi analysis. Finally, for the neck length $l$ as the other insignificant influence factor, it is purposely selected at the median value of $3 \mathrm{~mm}$ for the consideration of weight and easy manufacturing of the window prototyping.

According to the above analysis, the final optimal set of control factors for the overall performance of the frequency range is determined as illustrated in Figure 9. The numerical results of the final optimal design show that the equivalent sound pressure levels at the frequencies of $630 \mathrm{~Hz}, 800 \mathrm{~Hz}$ and $1000 \mathrm{~Hz}$ are $98.68 \mathrm{dBA}, 96.31 \mathrm{dBA}$ and $94.05 \mathrm{dBA}$, respectively. The equivalent sound pressure level for the entire frequency range of $630-1000 \mathrm{~Hz}$ is $101.52 \mathrm{dBA}$. Comparisons between the final optimized set and the individual optimized sets under the frequencies of $630 \mathrm{~Hz}, 800 \mathrm{~Hz}$ and $1000 \mathrm{~Hz}$ are shown in Figure 10. It can be found that although the final optimized design has not achieved the best performance for all individual frequency, it has attained the second best in general. Furthermore, it is obvious that the final optimized design has the best performance over the entire frequency range. This is suggested that the proposed methodology for the optimization design of the configuration of resonators for an LRSCs window is workable.

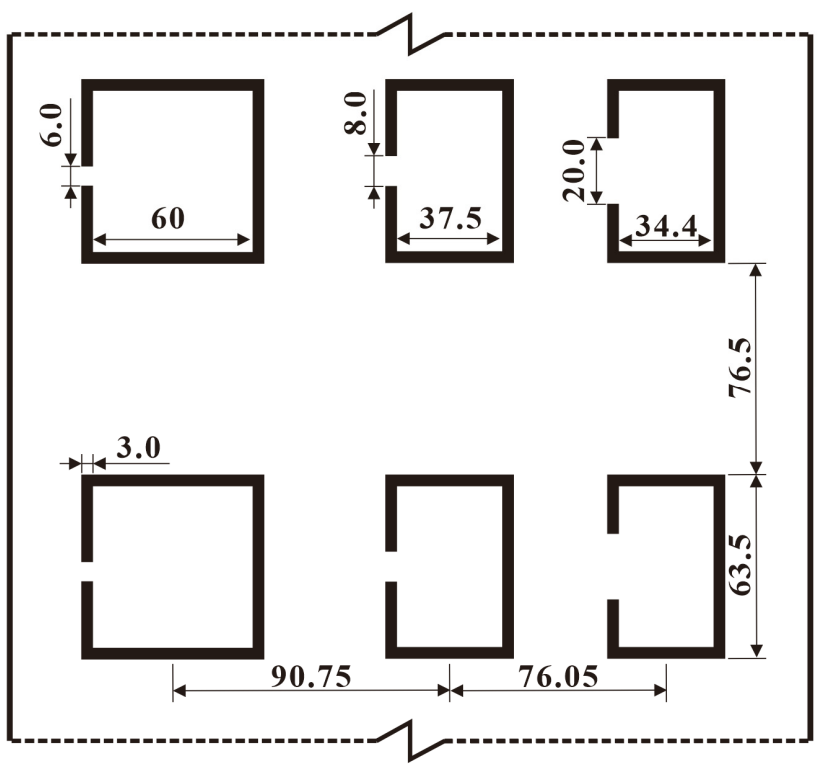

Figure 9. Schematic of the final optimized configuration of LRSCs (units: mm). 


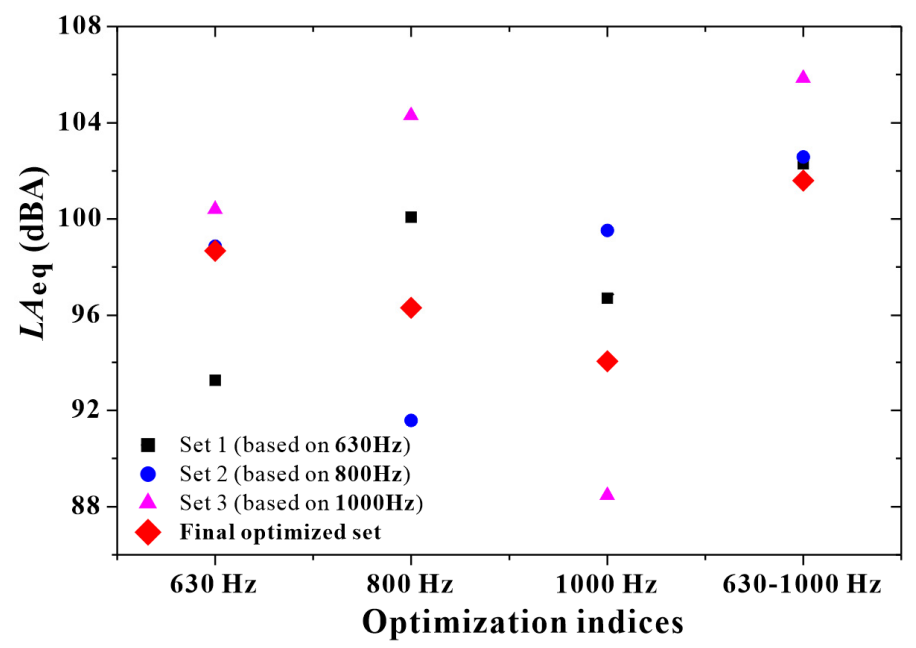

Figure 10. Comparisons of the acoustic performance of the optimized sets of parameters under different optimization indices.

\subsection{Experimental Results and Comparison}

In order to verify the acoustic performance of the final optimized LRSCs window, a prototype of the LRSCs window with the design parameters in Figure 9 was fabricated. Experiments were then carried out in a semi-anechoic chamber as introduced previously. As shown in Figure 11, the experimental results are presented and the comparisons between the experiment and simulation are illustrated.
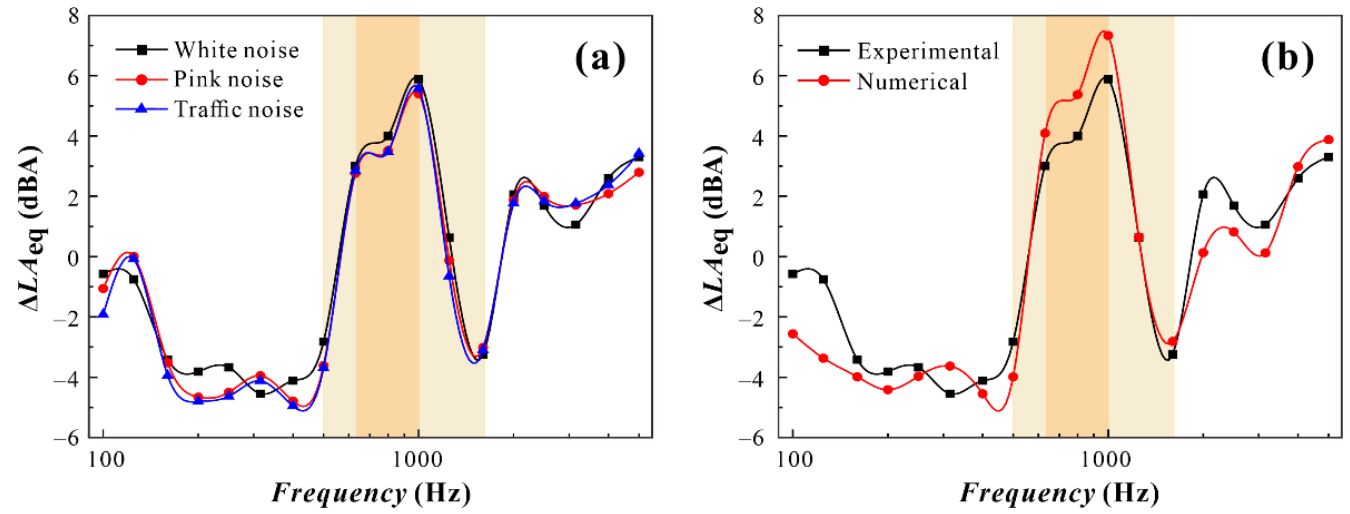

Figure 11. (a) The $\Delta L A_{e q}$ of three different noises; (b) Comparison of the $\Delta L A_{e q}$ for numerical and experimental results when noise was white noise.

Figure 11a shows the acoustic performances of the LRSCs window under three different noise sources, namely the white, pink and traffic noises. It can be seen that the LRSCs window has similar performance on the attenuation of these three noises, especially in the frequency range of 500-1600 Hz. This is expected since the LRSCs window is developed through the optimization of noise attenuation performance in the frequency range of 630-1000 Hz. The noise attenuation performances by the LRSCs window for different noises should be close to each other near this frequency range. The negative values of $\Delta L A_{e q}$ manifest that the noise attenuation performance by the LRSCs window is worse than the benchmark in the lower frequency region $(<500 \mathrm{~Hz})$. This is possibly due to the fact that in the lower frequency region where the resonance mechanism of noise reduction by the resonators is not actively functioned, the longer sound wavelength tends to have stronger reflection when it propagates through the LRSCs window. Furthermore, it is obvious that over the entire frequency range $(100-5000 \mathrm{~Hz})$, the best attenuation performance by the LRSCs window falls in the frequency range of $630-1000 \mathrm{~Hz}$, which is in accordance with the objective of the optimization efforts. In other words, the proposed optimization 
methodology in the design of resonator configuration is applicable and significant in actual applications. The results show that the developed LRSCs window with the current optimized design parameters can attenuate the traffic noise by $2.84 \mathrm{dBA}, 3.48 \mathrm{dBA}$, and $5.56 \mathrm{dBA}$ for the frequencies of $630 \mathrm{~Hz}, 800 \mathrm{~Hz}$ and $1000 \mathrm{~Hz}$, respectively, as shown in Table 9 . For the frequency range $630-1000 \mathrm{~Hz}$, the overall acoustic performance can be improved by $3.28 \mathrm{dBA}$.

Table 9. The $\Delta L A_{\text {eq }}$ of experiments for three noises and simulations.

\begin{tabular}{ccccc}
\hline Frequency & White Noise & Pink Noise & Traffic Noise & Simulation \\
\hline $630 \mathrm{~Hz}$ & 3.01 & 2.77 & 2.84 & 4.09 \\
$800 \mathrm{~Hz}$ & 4.00 & 3.51 & 3.48 & 5.38 \\
$1000 \mathrm{~Hz}$ & 5.89 & 5.40 & 5.56 & 7.34 \\
$630-1000 \mathrm{~Hz}$ & 3.53 & 3.15 & 3.28 & 5.49 \\
\hline
\end{tabular}

Figure $11 \mathrm{~b}$ shows the comparison between the experimental and numerical results. Since the point noise source is applied in the simulation, the experiment results of white noise are utilized for comparison. As can be seen, over the entire frequency range of $100-5000 \mathrm{~Hz}$, the trends and magnitudes of the experiment and simulation results are corresponding and particularly well compared in the frequency range of $630-1000 \mathrm{~Hz}$. This firstly suggests that the simulation model is feasible for the current numerical experiments and the reported simulation results are supposed to be convinced [19,32,33,35-37]. It is noted that the highest value of $\Delta L A_{e q}$ is occurred at $1000 \mathrm{~Hz}$ both in experiment and simulation, followed by $800 \mathrm{~Hz}$. This implies that the optimized resonator configuration for the LRSCs window is more effective in reducing the noise near $1000 \mathrm{~Hz}$, suggesting more pronounced resonant effects in this frequency.

In order to better understand the resonant effects for the current optimal configuration, the simulated map of the sound pressure level (SPL) by the LRSCs window at different resonant frequencies is demonstrated in Figure 12. For the resonators in the first column, the effective noise attenuation is found to be activated at the frequency of $586 \mathrm{~Hz}$ which is close to the designed frequency of $630 \mathrm{~Hz}$ for this column of resonators, as shown in Figure 12a. As also illustrated, the functions of the resonators in the second and third columns are almost null under this frequency. As shown in Figure 12b, for the second column resonators, the resonant frequency occurs at the frequency of $781 \mathrm{~Hz}$ which is closer to the designed frequency of $800 \mathrm{~Hz}$ as compared to the first column resonators. At this frequency, the resonators in the first column can still play a visible role in the noise attenuation while the third column is ineffective. This could explain the findings in Figure 11 that the current configuration of LRSCs is more effective in reducing noise at the frequency of $800 \mathrm{~Hz}$ than that at $630 \mathrm{~Hz}$. For the third column resonators, the resonant frequency is happening at the frequency of $1005 \mathrm{~Hz}$ which is almost coincided with the designed frequency of $1000 \mathrm{~Hz}$ as shown in Figure 12c. Aside from the third column of resonators, it can be noticed that the second column also exerts a significant impact on the noise reduction at this frequency. This could explain the best noise attenuation performance by the LRSCs window in the frequency of $1000 \mathrm{~Hz}$ as shown in Figure 11. 


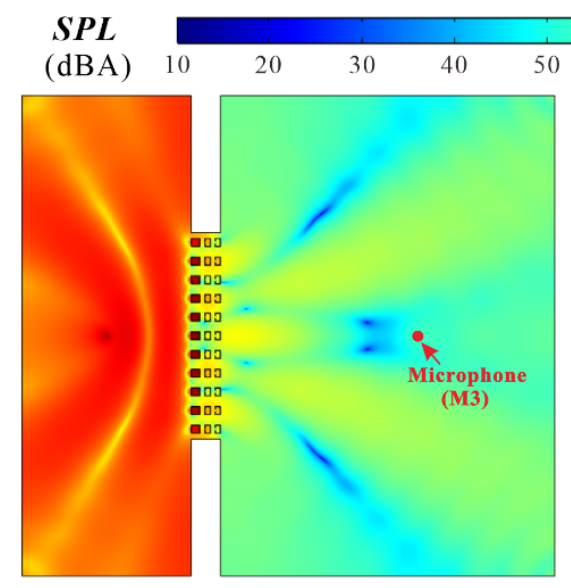

(a) $586 \mathrm{~Hz}$

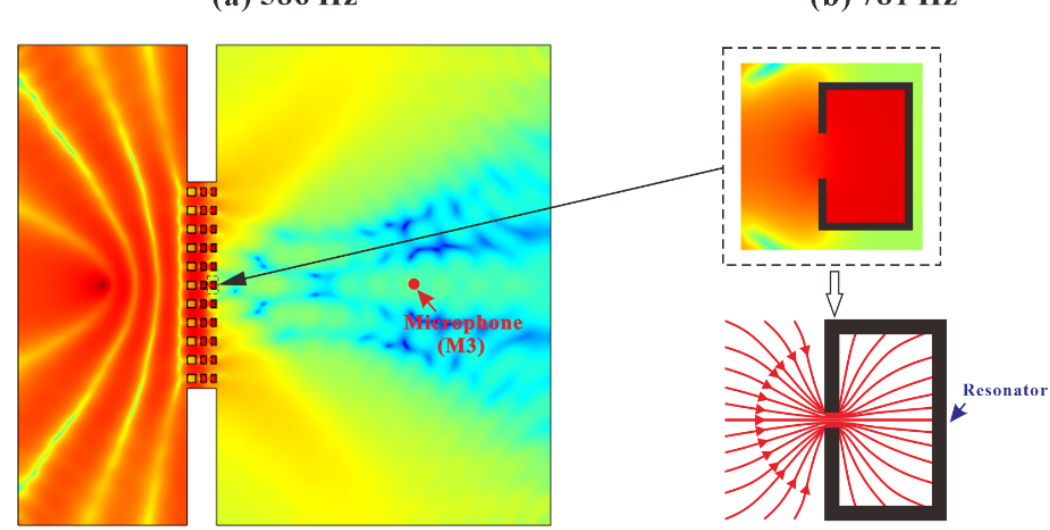

(c) $1005 \mathrm{~Hz}$

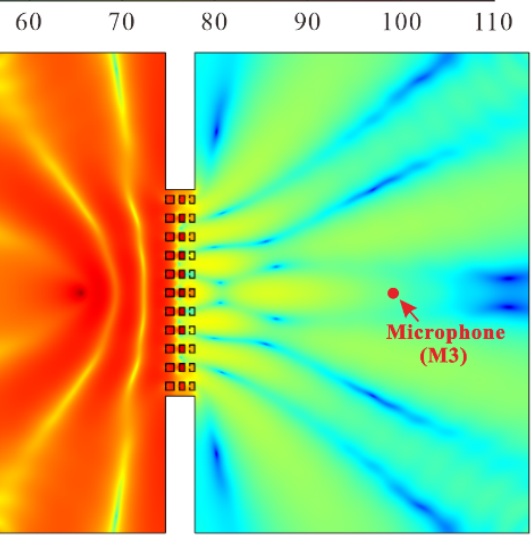

(b) $781 \mathrm{~Hz}$

Figure 12. The contour of SPL activated by LRSCs at different frequencies, microphone at M3. (a) $586 \mathrm{~Hz}$; (b) $781 \mathrm{~Hz}$; (c) $1005 \mathrm{~Hz}$.

\section{Conclusions}

Optimization methodology combining the methods of Taguchi and ANOVA analysis has been proposed to develop a more compact and better acoustic performance LRSCs window. Numerical experiments based on the orthogonal table designed by the Taguchi method were firstly conducted on the COMSOL Multiphysics platform to investigate the parametric effects on acoustic performance. Then, the SN ratio and ANOVA analysis were carried out to identify the parameters that have statistical significance and remarkable contributions on the desired performance. An optimal set of design parameters were finally determined and used for the fabrication of an LRSCs window prototype. Acoustic characteristics of the LRSCs window prototype were thereby scrutinized in a semi-anechoic chamber. The main conclusions can be drawn as follows:

1. Three optimal sets of design parameters have been explored at the targeted frequencies of $630 \mathrm{~Hz}, 800 \mathrm{~Hz}$ and $1000 \mathrm{~Hz}$ by the SN ratio analysis. The optimal set of parameters on the basis of the evaluated frequency is found to achieve the best noise attenuation performance on that frequency.

2. According to the ANOVA analysis of the numerical results, the slit size (a) has indicated the greatest influence on the overall noise reduction performance and followed by the cavity width $(b)$. Whereas, the effect of neck length $(l)$ is negligible.

3. With the combination of the $\mathrm{SN}$ ratio and ANOVA analysis, a comprehensive evaluation of the design parameters on the acoustic performance has been carried out to search after an optimal set of design parameters that performs the overall best noise attenuation performance over the frequency range of $630-1000 \mathrm{~Hz}$. The results of the final optimal design are in accordance with the design objective, suggesting that 
the proposed optimization methodology is applicable and effective in designing the geometries of resonators and their configurations for an LRSCs window.

4. Experimental results are found to be well compared with the simulation results, indicating that the applied numerical experiments are accurate and reliable. It further confirms the feasibility of using the current optimization methodology to develop compact LRSCs windows or similar applications for high noise reduction.

5. In comparison to the benchmark window on the mitigation of traffic noise, the equivalent SPL attenuation of the optimized LRSCs windows are $2.84 \mathrm{dBA}, 3.48 \mathrm{dBA}$ and $5.56 \mathrm{dBA}$ at the frequencies of $630 \mathrm{~Hz}, 800 \mathrm{~Hz}$ and $1000 \mathrm{~Hz}$, respectively, and the overall equivalent SPL attenuation is $3.28 \mathrm{dBA}$ in the frequency range of $630-1000 \mathrm{~Hz}$.

Author Contributions: Conceptualization, J.X., H.L., H.P.L.; methodology, J.X.; software and investigation, Y.H.; writing-original draft preparation, H.L. and Y.H.; writing-review and editing, J.X.; supervision, J.X., H.L.; resources, H.P.L.; funding acquisition, H.L. and J.X. All authors have read and agreed to the published version of the manuscript.

Funding: This research was funded by the National Natural Science Foundation of China [51908142], Natural Science Foundation of Guangdong Province [2019A1515012223, 2021A1515012269] and Guangzhou Basic Research Program—City School (College) Joint Funding Project [202102010384,202102010410].

Institutional Review Board Statement: Not applicable.

Informed Consent Statement: Not applicable.

Data Availability Statement: Data are available from the corresponding author on request.

Conflicts of Interest: The authors declare no conflict of interest.

\section{Nomenclature}

$y_{i} \quad$ Result of Test

CF Correction coefficient

$S_{Q} \quad$ Sum of squares for individual control factor

$F \quad$ Fisher ratio for individual factor

$\lambda \quad$ Contribution rate

$n \quad$ Number of tests

$\mathrm{SN}_{j} \quad \mathrm{SN}$ ratios of individual test

$f_{c} \quad$ Resonance frequency $(\mathrm{Hz})$

$v \quad$ Speed of sound in air $(\mathrm{m} / \mathrm{s})$

a Silt size of resonator $(\mathrm{mm})$

$a_{2} \quad$ Silt size of the second column resonator $(\mathrm{mm})$

$b \quad$ Inner width of resonator $(\mathrm{mm})$

$b_{2} \quad$ Inner width of the second column (mm)

$l \quad$ Length of the resonator neck ( $\mathrm{mm}$ )

$N \quad$ Number of Repeated Tests

$S_{T} \quad$ Sum of squares for all tests

$V_{\text {factor }}$ Variance of factor

$V_{\text {error }} \quad$ Variance of error

$m \quad$ Number of levels for individual factor

$\mathrm{SN}_{i} \quad$ Sum of SN ratios for a control factor at level $i(i=1,2$ and 3$)$

DOF Degree of freedom of a control factor

$S \quad$ Cross-sectional area of resonator opening $\left(\mathrm{mm}^{2}\right)$

$V \quad$ Volume of resonator cavity $\left(\mathrm{mm}^{3}\right)$

$a_{1} \quad$ Silt size of the fist column resonator $(\mathrm{mm})$

$a_{3} \quad$ Silt size of the third column resonator $(\mathrm{mm})$

$b_{1} \quad$ Inner width of the fist column resonator $(\mathrm{mm})$

$b_{3} \quad$ Inner width of the third column resonator $(\mathrm{mm})$

$c \quad$ Inner height of resonator $(\mathrm{mm})$ 


\section{References}

1. Dzhambov, A.; Tilov, B.; Markevych, I.; Dimitrova, D. Residential road traffic noise and general mental health in youth: The role of noise annoyance, neighborhood restorative quality, physical activity, and social cohesion as potential mediators. Environ. Int. 2017, 109, 1-9. [CrossRef] [PubMed]

2. Ma, J.; Li, C.; Kwan, M.P.; Kou, L.; Chai, Y. Assessing personal noise exposure and its relationship with mental health in Beijing based on individuals' space-time behavior. Environ. Int. 2020, 139, 105737. [CrossRef] [PubMed]

3. Sigalas, M.M.; Economou, E.N. Elestic and acoustic wave band structure. J. Sound Vib. 1992, 158, 377-382. [CrossRef]

4. Dowlin, J.P. Sonic band structure in fluids with periodic density variations. J. Acoust. Soc. Am. 1992, 91, 2539-2543. [CrossRef]

5. Kushwaha, M.S.; Halevi, P.; Dobrzynski, L.; Djafari-Rouhani, B. Acoustic band structure of periodic elastic composites. Phys. Rev. Lett. 1993, 71, 2022-2025. [CrossRef]

6. Sánchez-Pérez, J.V.; Caballero, D.; Mártinez-Sala, R.; Rubio, C.; Sánchez-Dehesa, J.; Meseguer, F.; Llinares, J.; Gálvez, F. Sound attenuation by a two-dimensional array of rigid cylinders. Phys. Rev. Lett. 1998, 80, 5325-5328. [CrossRef]

7. Kushwah, M.S.; Akjouj, A.; Djafari-Rouhani, B.; Dobrzynski, L.; Vasseur, J.O. Acoustic spectral gap and discrete transmission in slender tubes. Solid State Commun. 1998, 106, 659-663. [CrossRef]

8. Martínez-Sala, R.; Rubio, C.; García-Raffi, L.M.; Sánchez-Pérez, J.V.; Sánchez-Pérez, E.A.; Llinares, J. Control of noise by trees arranged like sonic crystals. J. Sound Vib. 2006, 291, 100-106. [CrossRef]

9. Khelif, A.; Choujaa, A.; Benchabane, S. Guiding and bending of acoustic waves in highly confined phononic crystal waveguides. Appl. Phys. Lett. 2004, 84, 4400-4402. [CrossRef]

10. Kumar, S.; Lee, H.P. Recent advances in acoustic metamaterials for simultaneous sound attenuation and air ventilation performances. Crystals 2020, 10, 686. [CrossRef]

11. Thota, M.; Wang, K.W. Reconfigurable origami sonic barriers with tunable bandgaps for traffic noise mitigation. J. Appl. Phys. 2017, 122, 154901. [CrossRef]

12. Sanchez-Perez, J.V.; Rubio, C.; Martinez-Sala, R.; Sanchez-Grandia, R.; Gomez, V. Acoustic barriers based on periodic arrays of scatterers. Appl. Phys. Lett. 2002, 81, 5240-5242. [CrossRef]

13. Lee, H.M.; Lim, K.M.; Lee, H.P. A maze structure for sound attenuation. Appl. Acoust. 2017, 115, 88-92. [CrossRef]

14. Huang, J.K.; Liu, Y.F.; Li, Y.G. Trees as large-scale natural phononic crystals: Simulation and experimental verification. Int. Soil Water Conse. 2019, 7, 196-202. [CrossRef]

15. Liu, Z.Y.; Zhang, X.X.; Mao, Y.W.; Zhu, Y.Y.; Yang, Z.Y.; Chan, C.T.; Sheng, P. Locally resonant sonic materials. Science 2000, 289, 1734-1736. [CrossRef]

16. Cui, Z.Y.; Chen, T.N.; Chen, H.L.; Su, Y.P. Experimental and calculated research on a large band gap constituting of tubes with periodic narrow slits. Appl. Acoust. 2009, 70, 1087-1093. [CrossRef]

17. Lardeau, A.; Groby, J.-P.; Romero-García, V. Broadband transmission loss using the overlap of resonances in 3D sonic crystals. Crystals 2016, 6, 51. [CrossRef]

18. Chen, C.M.; Guo, Z.F.; Liu, S.T.; Feng, H.D.; Qiao, C.X. Effect of cavity structure on acoustic characteristics of phononic crystals based on double-layer plates. Crystals 2020, 10, 995. [CrossRef]

19. Mohapatra, K.; Jena, D.P. Insertion loss of sonic crystal made with multi resonant shells. Appl. Acoust. 2021, 171, 107676. [CrossRef]

20. Wang, Z.G.; Lee, S.H.; Kim, C.K.; Park, C.M.; Nahm, K.; Nikitov, S.A. Acoustic wave propagation in one-dimensional phononic crystals containing Helmholtz resonators. J. Appl. Phys. 2008, 103, 064907. [CrossRef]

21. Wang, X.P.; Sun, H.; Chen, T.N.; Wang, X.G. Enhanced acoustic localization in the two-dimensional phononic crystals with slit tube defect. Phys. Lett. A 2019, 383, 125918. [CrossRef]

22. Jiménez, N.; Huang, W.; Romero-García, V.; Pagneux, V.; Groby, J.P. Ultra-thin metamaterial for perfect and quasi-omnidirectional sound absorption. Appl. Phys. Lett. 2016, 109, 121902. [CrossRef]

23. Gupta, A.K.; Gupta, N. Development of shape of helmholtz resonator cavity for attenuation of low frequency noise of pure reactive muffler. Inter. J. Scient. Develop. Res. 2016, 1, 37-42.

24. Selamet, A.; Lee, I. Helmholtz resonator with extended neck. J. Acoust. Soc. Am. 2003, 113, 1975-1985. [CrossRef]

25. Li, J.B.; Wang, Y.S.; Zhang, C.Z. Tuning of acoustic bandgaps in phononic crystals with helmholtz resonators. J. Vib. Acoust. 2013, 135, 31015. [CrossRef]

26. Yang, A.; He, W.; Zhang, J.T.; Zhu, L.; Yu, L.G.; Ma, J.; Zou, Y.; Li, M.; Wu, Y. Multi-resonance tunneling of acoustic waves in two-dimensional locally-resonant phononic crystals. Eur. Phys. J. Appl. Phys. 2017, 77, 21101. [CrossRef]

27. Lee, H.M.; Lim, K.M.; Lee, H.P. Experimental and numerical studies on the design of a sonic crystal window. J. Vibroeng. 2017, 19, 2224-2233. [CrossRef]

28. Lee, H.M.; Lim, K.M.; Lee, H.P. Environmental and sound divergence effects on the performance of rectangular sonic crystals with Helmholtz resonators. J. Vib. Control 2017, 24, 2483-2493. [CrossRef]

29. Lee, H.M.; Tan, L.B.; Lim, K.M.; Lee, H.P. Sound quality experiments in a student hostel with newly designed sonic crystal window. Acoust Aust. 2017, 45, 505-514. [CrossRef]

30. Everest, F.A.; Pohlmann, K.C. Master Handbook of Acoustics, 5th ed; McGraw-Hill: New York, NY, USA, 2009 ; pp. $209-219$.

31. Comsol. Available online: https://www.comsol.com/ (accessed on 3 December 2021). 
32. Elford, D.P.; Chalmers, L.; Kusmartsev, F.V.; Swallowe, G.M. Matryoshka locally resonant sonic crystal. J. Acoust. Soc. Am. 2011, 130, 2746-2755. [CrossRef]

33. Radosz, J. Acoustic performance of noise barrier based on sonic crystals with resonant elements. Appl. Acoust. 2019, 155, 492-499. [CrossRef]

34. Ji, P.F.; Hu, W.L.; Yang, J. Development of an acoustic filter for parametric loudspeaker using phononic crystals. Ultrasonics 2016, 67, 160-167. [CrossRef] [PubMed]

35. Wang, X.N.; Zhou, Y.D.; Sang, J.Q.; Zhu, W.Y. A generalized model for space-coiling resonators. Appl. Acoust. 2020, 158, 107045. [CrossRef]

36. Dandsena, J.; Mohapatra, K.; Satapathy, A.K.; Jena, D.P. Noise control of outdoor unit of split type air-conditioner using periodic scatterers made with array of Helmholtz resonators. Appl. Acoust. 2021, 179, 108054. [CrossRef]

37. Wang, X.P.; Jiang, P.; Chen, T.N.; Yu, K.P. Frequency characteristics of defect states in a two-dimensional phononic crystal with slit structure. Int. J. Mod. Phys. B 2016, 30, 1650025. [CrossRef] 